\title{
Miscellany
}

\section{The Mental Health Foundation}

The Learning Disabilities Committee of the Mental Health Foundation has grants available for work on challenging behaviour. All applications must be on a standard Mental Health Foundation application form and the deadline for receipt of these is 30 September 1993.

The Substance Abuse Committee of the Foundation is keen to attract innovative research and project proposals in the field of substance abuse. To be considered for funding, potential applicants must submit a draft proposal for consideration at a meeting to be held on 18 October 1993. A small sample of these will be invited to submit a more detailed application to a grant giving meeting on 17 March 1994. The deadline for receipt of draft proposals is 30 September 1993.

Further information about both projects: Justin Russell, Senior Projects Officer, The Mental Health Foundation, 37 Mortimer Street, London WIN 7RJ (telephone 071 580 0145; fax 071631 3868).

The Mental Health Foundation also wishes to encourage innovative projects and foster sound research on the subject of the mentally disordered offender. Funds will be allocated by the Committee at its meeting in October 1993. Applications should reach the Foundation by 1 September 1993. Further details: Caroline Newman, Secretary, Committee on the Mentally Disordered Offender, The Mental Health Foundation, 37 Mortimer Street, London WIN 7RJ.

\section{Manic depression and public education}

The Manic Depression Training Consultancy has been formed to meet public and professional need for courses, conferences and seminars on all aspects of manic depression and similar disorders. Publications will be developed and will include audio and videotapes. Further information: Mr Robert Gregory or Mrs Pam Jenkinson, Co-Directors, Manic Depression
Training Consultancy, 36 Lorn Road, Stockwell, London SW9 0AD.

\section{New publications}

Making Sense of Treatments and Drugs: Lithium has been published jointly by MIND and the Manic Depression Fellowship and is available at $£ 2.00$ plus stamped addressed envelope from: MIND Publications, 1st Floor, Kemp House, 152-160 City Road, London ECIV 2NP.

Special Edition is a new magazine giving information about policy and strategic issues within the Special Hospitals Service Authority and is being circulated within the hospitals and to interested groups outside to improve awareness of developments within forensic psychiatry in the hospitals. Further information can be obtained from Nuala O'Brien, Public Relations Manager, Special Hospitals Service Authority, Charles House, 375 Kensington High Street, London W14 8QH.

\section{Psychophysiology}

From 1993, Psychophysiology (published by the Society for Psychophysiological Research (SPR) for 30 years) will be published by Cambridge University Press. It will include papers from the fields of cognitive science and cognitive neuroscience, behavioural medicine and health psychology, psychiatry, psychopathology and clinical psychology, and applied psychology. Further information: Publishing Division, Cambridge University Press, The Edinburgh Building, Shaftesbury Road, Cambridge CB2 2RU.

\section{Award}

Dr Chunilal Roy, a Fellow of the College, has been awarded a knighthood by the Order of Saint John for his humanitarian work. Dr Roy is now Clinical Professor of Psychiatry at the University of British Columbia. 